\title{
Gambaran Infeksi Enterobiasis, Ascariasis, Trichuriasis, dan Infeksi Hookworm, pada Murid Sekolah Dasar 03 Plumbon Karanganyar dan Sekolah Dasar Negri Pajang I
}

Description of infection of Enterobiasis, Ascariasis, Trichuriasis, and Hookworm infection, on stool samples of elementary school children 03 Plumbon Karanganyar and elementary school children Pajang I

Tri Mulyowati*

Fakultas Ilmu Kesehatan Universitas Setia Budi

*Corresponding author: trimulyowati.usb81@gmail.com

\begin{abstract}
ABSTRAK
Infeksi kecacingan termasuk Negleted Tropical Disease. Infeksi dan penyakit yang disebabkan kelompok cacing penting bagi manusia karena seringkali mempunyai dampak serius pada penderita maupun masyarakat. Anak-anak usia sekolah biasanya memiliki intensitas infeksi cacing tertinggi pada semua kelompok usia. WHO mencanangkan progam untuk membebaskan kecacingan pada tahun 2020 setidaknya 75\% dari perkiraan 873 juta anak di daerah yang prevalensinya tinggi. WHO melakukan kampanye cacingan pertama di lakukan di mesir tahun 2016 dengan cara membentuk Endemic Disease Departement dan membagikan 4 juta tablet kunyah albendazole dengan tujuan supaya prevalensi parasit intestinal bisa terkurangi dan bisa mencegah komplikasi misalnya diare, anemia, gizi buruk sehingga bisa mempengaruhi tingkat pertumbuhan dan konsentrasi pada Anak usia sekolah.

Penelitian ini bertujuan untuk mengetahui gambaran infeksi Enterobiasis, Ascariasis, Trichuriasis dan infeksi hookworm pada murid Sekolah Dasar 03 Plumbon Karanganyar dan SDN Pajang I . Metode penelitian menggunakan pendekatan Crossectional. Metode pemeriksaan menggunakan metode pemeriksaan feces secara langsung.

Hasil yang didapatkan pada pemeriksaan makroskopis pada sampel feces murid Sekolah Dasar 03 Plumbon Kranganyar dan SDN Pajang I tidak menunjukkan abnormal sedangkan pemeriksaan mikroskopis pada sampel feces murid Sekolah Dasar 03 Plumbon Karanganyar dan SDN Pajang Ijuga tdk ditemukan adanya parasit, serta persentase untuk Enterobiasis $0 \%$. Ascariasis 0\%, Trichuriasis 0\% dan Hookworm 0\%.
\end{abstract}

Kata kunci: enterobiasis, ascariasis, trichuriasis, hookworm, feces,

\section{ABSTRACT}

Worm infections include Negleted Tropical Disease. infections and diseases caused by a group of worms are important to humans because they often have a serious impact on the patient and society. School-age children typically have the highest intensity of helminth infections in all age groups. WHO procures a program to relieve worms by 2020 at least $75 \%$ of the estimated 873 million children in high prevalence areas. WHO conducted the first intestinal campaign in 2016 by establishing the Endemic Disease Department and distributing 4 million chewable tablets of albendazole in order to prevent the prevalence of intestinal parasites and prevent complications such as diarrhea, anemia, malnutrition that can affect the growth rate and concentration in school-age children.

This study aims to determine the description of infection Enterobiasis, Ascariasis, Trichuriasis and hookworm infection in elementary school students 03 Plumbon Karanganyar and SDN Pajang I. The research method used Crossectional approach. inspection method using stool inspection method directly.

The results obtained on macroscopic examination on feces sample of elementary school students 03 Plumbon Kranganyar and SDN Pajang I did not show abnormal while microscopic examination on feces sample of elementary school students 03 Plumbon Karanganyar and SDN Pajang I also found no parasite, and percentage for enterobiasis $0 \%$. Ascariasis 0\%, Trichuriasis 0\% and Hookworm 0\%.

Keyword: enterobiasis, ascariasis, trichuriasis, hookworm, feces,

\section{PENDAHULUAN}

Enterobiasis adalah infeksi yang disebabkan oleh Enterobius vermicularis. Kasus entero- biasis pada anak- anak sekolah umur 5-10 tahun cukup tinggi. Infeksi karena tertelanya telur melalui tangan yang terkontaminasi atau makanan. 
(Pusarawati dan Ideham, 2007). Nama lain Enterobius vermicularis adalah Oxyuris vermicularis, cacing kremi atau pinworm. Enterobius vermicularis hidup dalam usus besar. Siklus hidupnya mulai cacing dewasa akan melekatkan diri ke mukosa, cacing betina bertelur di kulit perianal dan menyebabkan gatal-gatal. Jumlah telur yang dihasilkan kirakira 11.000 butir telur berisi larva infektif (Irianto, 2009).

Ascaris lumbricoides merupakan parasit yang paling umum pada manusia. Parasit ini tersebar luas (Pusarawati, dkk 2014). Ascariasis adalah penyakit parasitik yang disebabkan oleh infeksi Ascaris lumbricoides. Kasusnya lebih sering terjadi pada anak-anak terutama umur 59 tahun dibandingkan orang dewasa. Prevalensi tertinggi di daerah yang beriklim panas dan lembab di mana keadaan hygiene dan kebersihan lingkungan kurang memadai. Kasus di Indonesia prevalensi lebih dari $70 \%$ (Hadidjaja dan Margono, 2011), Kasus di daerah Asia (73\%), di Afrika (12\%), Amerika latin (8\%) (Marty dan Neafle, 2000).

Trichuriasis adalah infeksi penyakit yang disebabkan oleh Trichuris trichiura. Berdasarkan data dari WHO sekitar 350 sampai 500 juta orang terinfeksi cacing ini. Prevalensi tertinggi terjadi pada anak usia 5-15 tahun, frekuensi di Indonesia tinggi berkisar 30-90\%. (Sungkar, 2009). Telur trichuris mudah sekali tumbuh dan berkembang pada tanah sehingga tanah liat merupakan sumber penularan utama. (Sandjaja, 2007). Nama lain Trichuris trichiura adalah cacing cambuk. Cacing cambuk tersebar luas di daerah tropis yang berhawa panas dan lembab dan hanya ditularkan dari manusia ke manusia. Trichuris trichiura dewasa melekatkan diri pada mukosa usus penderita, terutama di daerah sekum dan colon dengan membenamkan kepalanya di dinding usus (Soedarto, 2016).

Ankilostomiasis dan Nekatoriasis adalah penyakit yang disebabkan oleh cacing tambang (hookworm) yaitu Ancylostoma duodenale dan
Necator americanus. Penyakit cacing tambang menyerang semua umur dengan proporsi terbesar pada anak. Kasus di dunia diperkirakan menyerang 700- 900 juta orang dengan 1 juta liter darah yang hilang karena dihisap oleh cacing. Hasil penelitian menyebutkan bahwa angka kesakitan pada balita $50 \%$, anak usia 9 tahun sekitar $90 \%$. (Widoyono, 2008). Hasil penelitian yang dilakukan oleh Djarismawati dan Mardiana, 2008 menyebutkan bahwa murid Sekolah Dasar WGT-Taskin dari 83 sampel yang diperiksa di Jakarta Barat terinfeksi telur cacing 59,04 \% laki-laki dan perempuan 40,96\%. Sampel dari SD-WGT-Taskin di Jakarta Timur, positif telur cacing 66,67 \% murid laki-laki dan dan $33,33 \%$ murid perempuan.

\section{METODE PENELITIAN}

Penelitian ini menggunakan penelitian observasional pendekatan Cross Sectional .

Tempat dan waktu penelitian: penelitian dilakukan di Laboratorium Parasitologi Universitas Setia Budi Surakarta pada bulan September 2017

Populasi: seluruh murid SD 03 Plumbon Karanganyar dan SDN Pajang.

Sampel: sampel diambil sebanyak 1 kelas dari murid SD 03 Plumbon Karanganyar dan 1 kelas SDN Pajang .

Kriteria Sampel: diambil sampel feces dari murid dengan usia 9-11 tahun

\section{Prosedur}

1. Persiapan probandus dan cara mengambil sampel feces

a. Menjelaskan kepada murid SD kelas 4 mengenai tujuan pemeriksaan feces dan meminta persetujuan

b. Menunjukkan sikap ramah kepada probandus

c. Membagikan pot sampel yang sudah kita kasih label

d. Menjelaskan kepada murid-murid SD Kelas 4 bahwa tinja yang akan diperiksa dikumpulkan pada tempat yang bersih yaitu 
penampung dari bahan plastik yang dapat ditutup rapat, tinja masih dalam keadaan segar, tidak boleh tercampur dengan air seni penderita, minyak, garam aluminium, magnesium, barium dan bismuth

e. tinja yang sudah dikeluarkan langsung dikumpulkan maksimal 1-2 jam sudah diperiksa di Laboratorium Parasitologi Universitas Setia Budi.

2. Pemeriksaan Feces metode langsung

a. Pemeriksaan makroskopis

Sebelum dilakukan pemeriksaan mikroskopis, dilakukan pemeriksaan makroskopis dengan memperhatikan hal-hal berikut

1) Warna : tinja yang dibiarkan pada udara menjadi lebih tua karena terbentuknya lebih banyak urobilin dan urobilinogen yang diekskresikan lewat usus.

2) Bau : normal disebabkan adanya indol, skatol dan asam butirat

3) Konsistensi : tinja normal agak lunak dengan mempunyai bentuk.

4) Lendir : adanya lendir mengindikasikan adanya rangsangan atau radang dinding usus.

5) Darah : dengan melihat apakah ada darah segar, coklat atau hitam, bercampur baur jadi satu atau di bagian luar saja.

6) Parasit : Cacing Ascaris, ancylostoma dll. (Gandasoebrata, 2010)

b. Pemeriksaan mikroskopis

Alat dan bahan : Sampel feces, sarung tangan, sabun cuci tangan, deck glass, masker, lidi, pensil untuk label, larutan eosin, larutan lugol, mikroskop.

Membuat pewarnaan sediaan langsung :

1) Menulis identitas pasien pada obyek glass dengan spidol

2) Memakai sarung tangan

3) Meletakkan obyek glass mendatar di atas meja

4) Meneteskan 1 tetes lugol pada kaca tengah kiri dan 1 tetes eosin pada tengah kanan dari obyek glass
5) Mengambil sedikit feces (bagian yang berlendir) dengan lidi dan mencampur feces dengan rata

6) Feces yang sudah tercampur dengan eosin ditutup dengan gelas penutup, menghisap cairan yang berlebih dengan kertas isap,

7) Melepas sarung tangan dan membuang ke tempat sampah yang aman

8) mengamati preparat di bawah mikroskop dengan obyektif 10x, atau 40x

9) Interprestasi hasil : melaporkan semua jenis parasit yang ditemukan

(+) jika ditemukan telur Ascaris lumbricoides, Trichuris trichiura, Hooworm pada sampel feces

(-) jika tidak ditemukan telur Ascaris lumbricoides, Trichuris trichiura, Hooworm pada sediaan feces dalam 100 lapang pandang (Wahyuni, 2013) Rumus menghitung prevalensi 1. Prevalensi seluruh cacing $=$ $\sum$ spesimen positif minimal 1 jenis cacing $\mathrm{x} \quad 100 \% \mathrm{Jml}$ spesimen $\mathrm{yg}$ diperiksa

2. Prevalensi spesies cacing $=$

Jml spesimen positif telur x $100 \% \mathrm{Jml}$ spesimen yg diperiksa

\section{HASIL DAN PEMBAHASAN}

1. Hasil Pemeriksaan Makroskopis

Berdasarkan hasil pemeriksaan makroskopis pada sampel anak SD 03 Plumbon Karanganyar didapatkan hasil semua sampel yang berjumlah 26 menunjukkan warna normal, konsistensi normal, bau normal, dan tidak ditemukan adanya lender, darah dan cacing dewasa (Tabel 1).

Berdasarkan hasil pemeriksaan makroskopis pada sampel anak SDN Pajang didapatkan hasil semua sampel yang berjumlah 26 menunjukkan warna normal, konsistensi normal, bau normal, dan tidak ditemukan adanya lendir, darah dan cacing dewasa (Tabel2). 
Tabel 1. Hasil pemeriksaan makroskopis sampel feces anak - anak SD kelas IV SD 03 Plumbon Karanganyar

\begin{tabular}{|c|c|c|c|c|c|c|c|c|}
\hline \multirow[t]{2}{*}{ No } & \multirow[t]{2}{*}{ Jenis Kelamin } & \multirow[t]{2}{*}{ Umur } & \multicolumn{6}{|c|}{ Makroskopis } \\
\hline & & & Warna & $\mathrm{Bau}$ & konsistensi & lendir & darah & parasit \\
\hline 1 & Laki- laki & 10 th & Coklat & Khas & Padat & - & - & - \\
\hline 2 & Perempuan & 10 th & Coklat kekuningan & Khas & Agak padat & - & - & - \\
\hline 3 & Perempuan & 10 th & Coklat tua & Khas & Padat & - & - & - \\
\hline 4 & Laki-laki & 8 th & Coklat kehitaman & Khas & Padat & - & - & - \\
\hline 5 & Perempuan & 11 th & Coklat & Khas & Lembek & - & - & - \\
\hline 6 & Perempuan & 10 th & Coklat & Khas & Lembek & - & - & - \\
\hline 7 & Perempuan & 10 th & Coklat kehitaman & Khas & Lembek & - & - & - \\
\hline 8 & Perempuan & 10 th & Coklat & Khas & Agak padat & - & - & - \\
\hline 9 & Perempuan & 10 th & Coklat & Khas & Lembek & - & - & - \\
\hline 10 & Perempuan & 10 th & Coklat & Khas & Lembek & - & - & - \\
\hline 11 & perempuan & 10 th & Coklat kehitaman & Khas & Padat & - & - & - \\
\hline 12 & Laki -laki & 10 th & Coklat & Khas & Padat & - & - & - \\
\hline 13 & Laki- laki & 9 th & Coklat & Khas & Padat & - & - & - \\
\hline 14 & Laki-laki & 10 th & Coklat & Khas & Lembek & - & - & - \\
\hline 15 & Laki-laki & 10 th & Coklat kuning & Khas & Padat & - & - & - \\
\hline 16 & Laki -laki & 10 th & Coklat & Khas & Agak padat & - & - & - \\
\hline 17 & Laki- laki & 10 th & Coklat & Khas & Agak padat & - & - & - \\
\hline 18 & Laki-laki & 10 th & Coklat & Khas & Lembek & - & - & - \\
\hline 19 & Laki-laki & 10 th & Coklat & Khas & Lembek & - & - & - \\
\hline 20 & Laki- laki & 9 th & Coklat & Khas & Lembek & - & - & - \\
\hline 21 & Laki- laki & 10 th & Coklat & Khas & Padat & - & - & - \\
\hline 22 & Perempuan & 10 th & Coklat & Khas & Padat & - & - & - \\
\hline 23 & Laki- laki & 9 th & Coklat & Khas & Padat & - & - & - \\
\hline 24 & Laki- laki & 10 th & Coklat & Khas & Padat & - & - & - \\
\hline 25 & Laki- laki & 10 th & Coklat & Khas & Padat & - & - & - \\
\hline 26 & Laki-laki & 10 th & Coklat & Khas & Padat & - & - & - \\
\hline
\end{tabular}

Tabel 2. Hasil pemeriksaan makroskopis sampel feces anak - anak SDN Pajang

\begin{tabular}{|c|c|c|c|c|c|c|c|c|}
\hline \multirow[t]{2}{*}{ No } & \multirow[t]{2}{*}{ Jenis Kelamin } & \multirow[t]{2}{*}{ Umur } & \multicolumn{6}{|c|}{ Makroskopis } \\
\hline & & & Warna & Bau & konsistensi & lendir & darah & parasit \\
\hline 1 & Perempuan & 9 th & Coklat hitam & khas & padat & - & - & - \\
\hline 2 & Laki - laki & 9 th & Coklat tua & khas & padat & - & - & - \\
\hline 3 & Perempuan & 9 th & Coklat tua & khas & padat & - & - & - \\
\hline 4 & Laki-laki & 9 th & hitam & khas & padat & - & - & - \\
\hline 5 & Laki-laki & 9 th & Coklat hitam & khas & padat & - & - & - \\
\hline 6 & Perempuan & 10 th & Coklat muda & khas & lembek & - & - & - \\
\hline 7 & Laki -laki & 9 th & Hijau kehitaman & khas & lembek & - & - & - \\
\hline 8 & Perempuan & 9 th & Coklat kehitaman & khas & padat & - & - & - \\
\hline 9 & Perempuan & 9 th & Coklat kehitaman & khas & lembek & - & - & - \\
\hline 10 & Perempuan & 9 th & Coklat tua & khas & padat & - & - & - \\
\hline 11 & Laki-laki & 10 th & Coklat kehitaman & khas & padat & - & - & - \\
\hline 12 & Laki-laki & 10 th & Coklat kehitaman & khas & padat & - & - & - \\
\hline 13 & Perempuan & 9 th & coklat & khas & Padat & - & - & - \\
\hline 14 & Perempuan & 9 th & Coklat tua & khas & lembek & - & - & - \\
\hline 15 & Laki-laki & 9 th & Coklat kehitaman & khas & lembek & - & - & - \\
\hline 16 & Perempuan & 9 th & coklat & khas & Lembek & - & - & - \\
\hline 17 & Laki-laki & 10 th & Kuning kehijauan & khas & lembek & - & - & - \\
\hline 18 & Perempuan & 9 th & Coklat tua & Khas & padat & - & - & - \\
\hline
\end{tabular}

Tabel 3. Persentase hasil pemeriksaan Enterobius vermicularis, Ascaris lumbricoides, Trichuris trichiura, Hookworm pada sampel Feces Anak SD 03 Plumbon Karanganyar.

\begin{tabular}{|l|l|l|l|l|}
\hline No & Spesies & Hasil pemeriksaan & Jumlah sampel & Persentase (\%) \\
\hline 1 & Hookworm & Negatif & 26 & 0 \\
\hline 2 & Oxyuris vermicularis & Negatif & 26 & 0 \\
\hline 3 & Ascaris lumbricoides & Negatif & 26 & 0 \\
\hline 4 & Trichuris trichiura & Negatif & 26 & 0 \\
\hline
\end{tabular}

Tabel 4. Persentase hasil pemeriksaan Enterobius vermicularis, Ascaris lumbricoides, Trichuris trichiura, Hookworm pada sampel Feces Anak SD N Pajang I Surakarta.

\begin{tabular}{|l|l|l|l|l|}
\hline No & Spesies & Hasil pemeriksaan & Jumlah sampel & Persentase (\%) \\
\hline 1 & Hookworm & Negatif & 18 & 0 \\
\hline 2 & Oxyuris vermicularis & Negatif & 18 & 0 \\
\hline 3 & Ascaris lumbricoides & Negatif & 18 & 0 \\
\hline 4 & Trichuris trichiura & Negatif & 18 & 0 \\
\hline
\end{tabular}


2. Hasil Pemeriksaan Mikroskopis dengan metode langsung

Hasil pemeriksaan terhadap feces anak SD 03 Plumbon Karanganyar diperoleh hasil untuk Ascaris lumbricoides, Trichuris trichiura, Hookworm dan Oxyuris vermicularis negatif (Tabel3).

Hasil pemeriksaan makroskopis sampel feces anak-anak SD 03 Plumbon Karanganyar dan SDN Pajang I menunjukkan bahwa pemeriksaan makroskopis tdk menunjukkan ciri-ciri abnormal pada feces. Telur cacing dapat ditemukan pada setiap specimen namun pada tinja cair kesempatan menemukan telur berkurang, cacing Trichuris dewasa dan Ascaris kadangkadang dapat ditemukan pada permukaan atau di dalam tinja. Adanya darah atau lendir di dalam atau di atas specimen merupakan petunjuk adanya infeksi. Tinja yang berwarna kehitaman menunjukkan perdarahan di usus bagian atas darah segar merupakan akibat perdarahan di bagian bawah usus. (Bruckner dan Garcia, 1996).

Hasil pemeriksaan mikroskopis pada sampel feces menggunakan metode langsung juga tidak menunjukkan adanya parasit di dalam sampel feces murid Sekolah Dasar 03 Plumbon Karanganyar dan SDN Pajang I baik Enterobius vermicularis, Ascaris lumbricoides, Trichuris trichiura dan Hookworm. Hal ini memungkinkan infeksi kecacingan yang terjadi di lingkungan tersebut rendah, dengan adanya perilaku hidup sehat dan bersih setiap murid bisa menekan terjadinya infeksi kecacingan. Presentasi nilai PHBS yang mencakup sehat utama dan paripurna di Jawa Tengah yaitu apabila mencapai nilai lebih dari $74,67 \%$, terdapat $5 \mathrm{Ka}$ bupaten yang memiliki PHBS dengan nilai di atas $90 \%$ di provinsi Jawa Tengah, kabupaten tersebut yaitu Kota Semarang (90,1\%), Sukoharjo(91,5\%), Karanganyar (92,5\%), Kota Surakarta $(92,0 \%)$ dan yang tertinggi adalah Kota Pekalongan (93,9\%) (Dinkes Jateng, 2013).
Hasil penelitian menunjukkan ascariasis dalam kategori rendah sebesar $0 \%$ (Kemenkes RI,2012). Kriteria dikatakan prevalensi tinggi pada ascariasis seperti yang dilakukan oleh Rahayu tahun 2006 dimana hasil yang didapatkan 65,22\%. Hal ini karena struktur morfologi telur Ascaris lumbricoides lebih kompleks, mempunyai lapisan luar yg bisa melawan rintangan ketika berada di lingkungan. Hasil penelitian pada murid Sekolah Dasar 03 Plumbon dan SDN Pajang juga rendah (0\%). Prevalensi tinggi pernah didapat dari data dari hasil penelitian yang dilakukan oleh Rosdania tahun 2016 tentang enterobiasis menunjukan sebagian besar responden yang ikut dalam penelitian berumur 8 tahun yaitu sebanyak 17 responden (37,8\%), dengan angka kejadian enterobiasis yang hampir merata di seluruh golongan umur yang menjadi responden, hal tersebut sesuai dengan yang diungkapkan dalam penelitian oleh Celizsoz et al. (2010) bahwa prevalensi enterobiasis cenderung lebih tinggi dan merata pada seluruh golongan umur pada anak yang berusia 5-12 tahun. Personal hygiene seperti mencuci tangan sebelum makan dan setelah defekasi memiliki kaitan yang erat terhadap infeksi enterobiasis pada anak (Suraweera et al., 2015)

\section{KESIMPULAN}

1. Tidak ditemukan adanya infeksi Enterobiasis, Ascariasis, Trichuriasis, infeksi hookworm pada Murid Sekolah Dasar Negri 03 Plumbon Karanganyar dan SDN Pajang I

2. Persentase kejadian Enterobiasis pada murid Sekolah Dasar 03 Plumbon Karanganyar dan SDN Pajang I sebesar $0 \%$, infeksi Ascariasis 0\% dan infeksi hookworm sebesar $0 \%$.

\section{DAFTAR PUSTAKA}

Bruckner, D.A, Garcia. L.S , 1996. Diagnostik Parsitologi Kedokteran. Jakarta: EGC.

Celiksoz, A., Mehmet, A., Serpil, D., Yasemin, A. O., Ahmed, A., 2010. Effect of Enterobiasis on Primary School Children. African Journal of Microbiology Reserch Vol.4, p.634-639. 
Dinas Kesehatan Jawa Tengah. 2013. Buku Profil Kesehatan Provinsi Jawa Tengah Tahun 2012. Jawa Tengah: Dinas Kesehatan Jateng

Djarismawati, mardiana. 2008. Prevalensi cacing usus pada murid Sekolah Dasar Wajib Belajar Pelayanan Gerakan Terpadu Pengentasan Kemiskinan Daerah Kumuh di Wilayah DKI Jakarta. Jurnal Ekologi Kesehatan. Vol 7 No 2 hal $769-774$

Gandasoebrata, 2010. Penuntun Laboratorium Klinik. Jakarta: Dian Rakyat.

Irianto, K.2009. Panduan praktikum Parasitologi Dasar untuk Paramedis dan Non Medis. Bandung: Yrama Widya.

Kementrian Kesehatan RI. 2012. Pedoman pengendalian Kecacingan. Jakarta: Kementrian Kesehatan Republik Indonesia

Margono S.S, Hadidjaja. P. 2011. Dasar Parasitologi Klinik. Jakarta: Badan Penerbit FKUI.

Pusarawati, S. Ideham, B. Kusmartisnawati, Tantular, I. S. Basuki, S. 2014. Atlas Parasitologi kedokteran. Jakarta: EGC.

Pusarawati, S, Ideham. B.2007. Helmintologi Kedokteran. Surabaya: University Airlangga Press.

Rahayu, S. E. 2006. Keberadaan Telur cacing Parasit pada Siswa SD di Sekitar Instalasi Pengolahan Air Limbah (IPAL) Terpadu kota Malang dan Perumahan di IPAL Terpadu. Jurnal Penelitian Hayati. 11: 105-112.
Rosdania, E.2016. Hubungan antara personal hygiene dan kejadian Infeksi enterobiasis pada siswa sekolah dasar Negeri mojorejo 01 bendosari sukoharjo. Surakarta.

Sandjaja, B. 2007. Parasitologi Kedokteran. Buku II: Helmintologi Kedokteran. Jakarta: Prestasi Pustaka Publisher.

Soedarto, 2016. Buku Ajar parasitologi Kedokteran. Edisi Kedua cetakan Pertama. Jakarta: Sagung Seto.

Sungkar, S. Sutanto, I. Sjarifuddin, P. K. Ismid, I. S. 2009. Buku Ajar Parasitologi Kedokteran. Edisi keempat. Jakarta: Departemen Parasitologi FKUI.

Suraweera, O. S. A., Lahiru, S. G., Devika, I., Susiji, W., 2015. Prevalence and Associate Factor of Enterobius vermicularis Infection in Childern from a Poor Urban Community in Sri Langka: A Cross-Sectional Study. International Journal of Reserch in Medical Science. 3(8): 1994-1999.

Wahyuni, S. 2013. Keterampilan membuat Apusan, mewarnai, Mengawetkan tinja, dan mengidentifikasi Parasit pada Apusan Tinja. Bagian Parsitologi Universitas hasanudin.

Widoyono.2008. Penyakit Tropis: Epidemiologi, Penularan, Pencegahan dan Pemberantasanya. Jakarta : Erlangga. 